Research Paper:

\title{
Relationship Between Nurses' Social Health and Quality of Life
}

\author{
Marhamat Farahaninia' $^{1}$ (D), Parvin Ehyaei ${ }^{1 *}$ id, Zahra Ahmadi ${ }^{1}$ (D), Hamid Haghani²
}

1. Department of Community Health Nursing, School of Nursing and Midwifery, Iran University of Medical Sciences, Tehran, Iran. 2. Department of Biostatistics, School of Public Health, Iran University of Medical Sciences, Tehran, Iran.

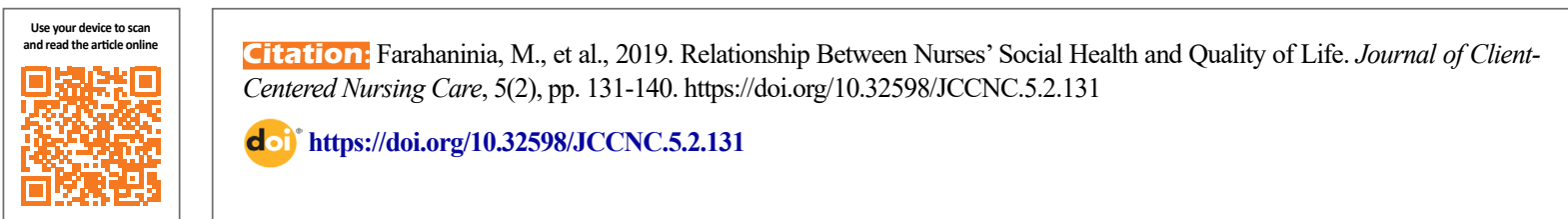

\section{(c) (1) (3)}

Article info:

Received: 13 Nov 2018

Accepted: 10 Mar 2019

Published: 01 May 2019

Keywords:

Social health, Quality of life, Nurses

\begin{abstract}
A B S T RA C T
Background: Social health is a crucial health aspect. Nurses are among the most important healthcare providers, and their quality of life bares great importance for providing quality healthcare. Therefore, this study aimed at determining the relationship between social health and quality of life nurses working in hospitals affiliated to Iran University of Medical Sciences (IUMS).
\end{abstract}

Methods: In this descriptive correlational study, 227 nurses were selected by cluster random sampling method from five hospitals affiliated to IUMS. The research instruments consisted of demographic information form, Keys Social Health questionnaire, and the 36-Item ShortForm Health Survey (SF-36). The obtained data were analyzed by descriptive tests (frequency, Mean \pm SD), as well as Analysis of Variance (ANOVA), Independent Samples t-test, Pearson's correlation coefficient, and multiple linear regressions in SPSS.

Results: The Mean \pm SD score of nurses' social health was $67.22 \pm 8.96$ with the lowest score in social solidarity $(9.16 \pm 2.34)$ and the highest score in social participation $(18.58 \pm 2.52)$. The Mean \pm SD score of nurses' quality of life was $64.62 \pm 18.6$. The lowest score related to energy and fatigue $(59.09 \pm 18.49)$, and the highest one was associated with the physical function (79.55 \pm 21.83 ). The collected results suggested a significant association between the quality of life and all aspects of social health $(\mathrm{P}<0.05)$. There was no significant relationship between social health and the demographic characteristics of the studied nurses $(\mathrm{P}>0.05)$. There was a significant relationship between the quality of life and age $(\mathrm{P}=0.046)$, work experience $(\mathrm{P}=0.03)$, marital status $(\mathrm{P}=0.024)$, and income $(\mathrm{P}=0.041)$.

Conclusion: The studied nurses' quality of life was associated with their social health; thus, it is suggested that the relevant managers and policymakers take serious steps to improve this group's quality of life and social health if interested in the quality of patient care.

\footnotetext{
* Corresponding Author:

Parvin Ehyaei, PhD.

Address: Department of Community Health Nursing, School of Nursing and Midwifery, Iran University of Medical Sciences, Tehran, Iran.

Tel: +98 (912) 2277526

E-mail: p.ehyaei2016@gmail.com
} 


\section{Highlights}

- Social health is a coherent, complex, and multi-dimensional concept.

- Social health has several components that show both quality and quantity of people's function in their social life.

- One of the important aspects of human life is the quality of life which comprises all aspects of health.

- All governments and organizations are obliged to provide the best health conditions for their people and staff.

- Nurses as an important part of health care system, is of particular importance.

- The quality of services provided by nurses directly affects the health care system.

\section{Plain Language Summary}

Nursing profession is associated with stressful factors higher than in other professions. These factors include patients' death, illness, high demands at work, heavy workload, lack of enough knowledge, conflicts and lack of support. Studies have shown that quality of life is affected by many individual, social and environmental factors. This study was designed to determine the relationship between nurses' social health and quality of life. Results showed a significant relationship between their social health and quality of life. This result can be used by healthcare officials to identify the necessary modifiable factors to improve social health and quality of life of nurses.

\section{Background}

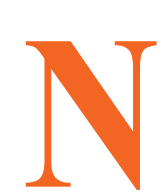

urses are the largest group of healthcare providers in all countries, and the quality of their provided services directly affects the healthcare system (Grady et al. 2008; World Health Organization, 2016).

Nursing has always been associated with more stressful factors than other professions. These factors include patients' death, illness, high task demands, heavy workload, inadequate knowledge, conflicts, and insufficient support (Maslakpak, Ahmadi \& Anoosheh 2011). It has been reported that $93 \%$ of nurses are regularly affected by stressors at a workplace, which may, in turn, deteriorate their relationships with family members and friends; consequently it may cause mood disorders (Jannati, Mohammadi \& Seyedfatemi 2011).

A vital aspect of human life is the quality of life; it comprises all aspects of life, including health (Mokarami, Taghavi \& Taban 2016). The quality of life concept has three characteristics. First, it focuses on individuals' life condition and their understanding of their own lives. Second, it is a multidimensional concept, covering numerous areas of life; e.g. housing conditions, training, employment, work-life balance, and access to services and their effects. Third, it collects the objective information of the living condition and the dimensions of the mind and the individual and society's behavior (Keles 2012).

Nurses are healthcare providers, whose every effort is to improve the quality of patient care. Ultimately, they enhance the care receivers' quality of life. However, the nurses' quality of life has not gained much attention (Hsu \& Kernohan 2006). The quality of life is affected by various personal and socio-environmental factors (Alaeenejad et al. 2017).

A significant factor influencing the quality of life is people's occupation (Aalaa et al. 2012). Healthcare services, especially nursing, are associated with triggers, like overwork, as a serious threat to the wellbeing and comfort related to their quality of life. Studies revealed that the quality of life of nurses is not high (Allaf Javadi et al. 2010; Ansari \& Abbasi 2015; Asarrodi Golafshan $\&$ Akabari 2011). Two-thirds of nurses are unsatisfied with their life quality. Moreover, their major dissatisfaction relates to the basic needs of their working life in the work environment that affects their lives and personal affairs (Dargahi \& Yazdi 2007). However, a study reported an appropriate quality of life level in $66.7 \%$ of nurses working in psychiatric wards (Fallahee Khoshknab et al. 2007).

Health is a coherent, complex, and multi-dimensional concept (Mozaffari et al. 2014). Most people consider 
health as an appropriate biopsychological status; however, biopsychosocial health status is more critical (Tavakol 2015). Social health focuses on the biopsychological aspect of health, and its social aspect is studied through centralizing the individuals. The terms quality of life, social health, and social wellbeing in their individual sense and in the society are defined as social health.

Social health has several components that together reflect the quality and extent of people's function in their social life (Aghdam et al. 2013). Social health is among the most important social concepts; it evaluates how individuals behave in society, which is possibly influenced by people's attitudes and lifestyles (Afshani et al. 2014). Social health dimensions include social cohesion, social acceptance, social participation, social prosperity, and social solidarity (Keyes \& Shapiro, 2004).

In general, social cohesion is the evaluation of the quality of individuals' relationships in the community and the social group to which they belong. Social acceptance is a favorable view towards others. Social prosperity indicates the assessment of the potential of the community. Social participation is considering one's self as a dynamic member of the community. Eventually, social solidarity understands society consciously, comprehensibly, and predictably (Afshani et al. 2014).

According to these dimensions, a healthy person is socially productive when considering community as meaningful, understandable, and capable of growth and prosperity. In addition, such person considers himself as a part of the social development process. Therefore, the content of the social health scale is a positive spectrum of the evaluation of individuals' experience in society (Keyes \& Shapiro 2004).

Health is a fundamental and social right of every human being. Thus, all governments and organizations are obliged to provide optimum health conditions for individuals. In this respect, the health of nurses as an important group of the healthcare system is of particular importance (Maghsoodi Hesabi \& Monfared 2015). Thus, it is essential to consider nurses' health threats, such as stress, sleeplessness due to rotating shift work, physical problems, and the complexity of nursing services. Additionally, addressing their health promotion as a key discipline to the healthcare system is crucial. Health promotion is a primary nursing principle that needs to be included in every nurses' life and work plan (Heidari \& Mohammadkhan-Kermanshahi, 2012).
In recent decades, the importance of social health has been emphasized in Iran; it has been considered as a fundamental criterion for the healthcare system (Noghabi Alhani \& Peyrovi 2013; Rostamigooran et al. 2013). However, few studies have extensively investigated the psychosocial risk factors associated with nurses' quality of life and occupational stress; while more attention is required in this area (Ramadan \& Ahmed 2015).

The nursing profession is associated with numerous issues. Moreover, professional responsibilities affect nurses' quality of life. Therefore, the present study determined the relationship between nurses' social health and quality of life.

\section{Materials and Methods}

In this descriptive-correlational study, 227 nurses from hospitals affiliated to Iran University of Medical Sciences (IUMS) were selected by cluster sampling method. The inclusion criteria were holding a nursing bachelor's degree and at least 6 months of work experience. The required sample size was calculated with the assumption that the correlation coefficient between the nurses' social health and quality of life is at least 0.2 to be considered as statistically significant (At 95\% confidence level, the test power of $80 \%$ ).

Initially, medical and educational hospitals were randomly selected. Then, the sample size was divided by the total number of nursing staff of all hospitals; next, the study participants were randomly selected from each hospital. The demographic information questionnaire included age, gender, work experience, employment status, marital status, and economic situation.

We used the Keyes Social Health questionnaire and the 36-Item Short-Form Health Survey (SF-36). The Keyes Social Health questionnaire has 20 questions, including social prosperity (four questions), social solidarity (three questions), social cohesion (three questions), social acceptance (five questions), and social participation (five questions). The scoring of this questionnaire is based on a five-point Likert-type scale (1. Absolutely disagree; 2. Disagree; 3. No opinion; 4. Agree; 5. Absolutely agree). The scores 20-46, 47-74, and 75-100 indicate low and poor (basic planning required), moderate (growing, but strengthening required), and high and good (maintenance required), respectively (Babapour Kheiroddin, Toosi \& Hekmati 2010).

The internal consistency (Cronbach's alpha coefficient) was obtained as $0.78,0.74,0.74,0.71,0.70$, 
and 0.77 for the whole scale social participation, social acceptance, social solidarity, social prosperity, and social cohesion, respectively. These findings indicate the desired reliability of this tool. The content validity of this questionnaire has also been confirmed (Babapour Kheiroddin, Toosi \& Hekmati 2010). Sharbatian also used this questionnaire in his study in 2012 investigating the reliability and validity of social health questionnaire on the students of Mashhad University of Medical Sciences. Based on their results, the Cronbach's alpha coefficient of social health was equal to 0.90 (Sharbatiyan, 2012). In this study; however, the Cronbach's alpha coefficient was estimated as 0.76 .

SF-36contains 36 questions that assess 8 subscales and two general scales of physical and mental health. In other words, physical health includes the subscales of physical function (ten items), physical limitations (four items), physical pain (two items), and general health (five questions). Mental health consists of a set of questions of social function (two questions), mental problems (three questions), mental health (five questions), and vitality (four questions). There is one more question which examines the change in a person's health during a specific period. The scores for each subscale ranging 0-100 indicate zero as the worst and 100 as the best state on the scale.

SPSS was used to analyze the obtained data. To describe the achieved data, frequency distribution table (for qualitative data), and mean and standard deviation (for quantitative data) were used. To determine the significance of inferential statistics, Analysis of Variance (ANOVA), Independent Samples t-test, Pearson correlation coefficient, and multiple linear regressions were applied. The significance level was set at 0.05 for all the tests.

\section{Results}

Based on the study results, the social health of $78.9 \%$ of the nurses was moderate. The social health of the nurses in the dimensions of prosperity, solidarity, cohesion, and participation was higher than the average of instrument scores, including $12,9,9$, and 15 , respectively; only in the acceptance dimension, the attained score (15) was lower than the average instrument score.

The Mean \pm SD age of nurses was $33.61 \pm 7.46$ years, and their working experience was $6.6 \pm 24.2$ years. A total of $89.8 \%$ of the studied nurses were female. Other demographic and clinical characteristics of the nurses are presented in Table 1. There was no significant relationship between social health and demographic charac- teristics $(\mathrm{P}<0.05)$; while the age $(\mathrm{P}=0.046)$, work experience $(\mathrm{P}=0.03)$, marital status $(\mathrm{P}=0.024)$, and income $(\mathrm{P}=0.041)$ were significantly associated with the nurses' quality of life (Table 1).

ANOVA results suggested a significant difference between the quality of life of different age groups; however, the LSD (Least Significant Difference) test indicated no significant difference in this regard. Moreover, the double-blind comparison revealed that the quality of life of nurses with 10-19 years of work experience was significantly less than those with a work experience of $<5$ years $(\mathrm{P}=0.006)$ and work experience of 5-9 years $(\mathrm{P}=0.017)$. There were no significant differences in other levels of work experience. The quality of life of married nurses was significantly less than that of the single ones $(\mathrm{P}=0.024)$. Income also had a significant relationship with the quality of life $(\mathrm{P}=0.041)$. The two-way comparison reflected that the quality of life of nurses with a moderate income was significantly less than that of those with a good income $(\mathrm{P}=0.041)$.

The Mean \pm SD score of nurses' social health was $67.22 \pm 8.96$. The lowest score related to the social solidarity dimension $(9.16 \pm 2.34)$, and the highest score belonged to social participation (18.58 \pm 3.52 ) (Table 2). Social health of $0.4 \%$ of nurses was poor, $78.9 \%$ were moderate, and $20.7 \%$ were high. The Mean \pm SD score of nurses' quality of life was $64.22 \pm 18.6$. The lowest score related to energy and fatigue $(59.09 \pm 18.49)$ and the highest score belonged to the physical function (79.55 \pm 21.83$)$. Biopsychological health evaluation suggested a higher physical health score (68.02 \pm 19.84$)$, compared to the mental health score $(61.63 \pm 20.36)$ (Table 3).

As per Table 4, there was a significant positive association between the quality of life and all dimensions of social health $(\mathrm{P}<0.05)$. By increasing the quality of life, all dimensions of social health increased. Social health had a significant positive correlation with all dimensions of the quality of life $(\mathrm{P}<0.05)$. This finding suggests that with an increase in social health, all dimensions of life quality increase. Furthermore, there was a significant positive correlation between the quality of life and social health $(\mathrm{P}<0.001)$. The determination coefficient between these two variables was 0.17 ; indicating that, the quality of life and social health had common $17 \%$ of the variance. 
Table 1. Comparing the mean scores of quality of life and social health according to the samples' characteristics

\begin{tabular}{|c|c|c|c|c|c|c|}
\hline & & & (Mean $\pm S D)$ & & (Mean士SD) & \\
\hline & & & Quality of Life & & Social Health & \\
\hline & Male & $202(89.8)$ & $62.93 \pm 16.28$ & $F=3.132$ & $67.2 \pm 10.99$ & $F=0.203$ \\
\hline Gender & Female & $23(10.2)$ & $65.09 \pm 18.72$ & $P=0.046$ & $67.37 \pm 8.71$ & $\mathrm{P}=0.816$ \\
\hline & $<30$ & $76(34.2)$ & $69.02 \pm 19.4$ & & $67.33 \pm 8.78$ & \\
\hline Age, $y$ & $30-39$ & $95(42.8)$ & $63.1 \pm 18.5$ & $\begin{array}{c}t=0.529 \\
d f=223 \\
P=0.598\end{array}$ & $67.17 \pm 9.4$ & $\begin{array}{c}t=0.87 \\
d f=223 \\
P=0.931\end{array}$ \\
\hline & $\geq 40$ & $51(23)$ & $61.69 \pm 16.38$ & & & \\
\hline & $<5$ & $73(32.7)$ & $68.05 \pm 19.42$ & & $67.11 \pm 9.03$ & \\
\hline Work & $5-9$ & $64(28.7)$ & $67.18 \pm 17.55$ & $F=3.074$ & $66.11 \pm 8.61$ & $F=1.157$ \\
\hline experience, $y$ & $10-19$ & 69 (30.9) & $59.61 \pm 16.83$ & $P=0.03$ & $67.18 \pm 8.92$ & $\mathrm{P}=0.327$ \\
\hline & $\geq 20$ & $17(7.6)$ & $63.41 \pm 20.32$ & & $71.05 \pm 8.86$ & \\
\hline & Official & 97 (43.9) & $63.13 \pm 19.44$ & & $68.17 \pm 9.13$ & \\
\hline Type of & Treaty & $31(14)$ & $63.09 \pm 19.37$ & $\begin{array}{l}F=1.148 \\
P=0.331\end{array}$ & $68.02 \pm 9.14$ & $F=0.995$ \\
\hline employment * & Contractual & $31(14)$ & $62.47 \pm 17.08$ & & $65.19 \pm 8.71$ & $P=0.396$ \\
\hline & Corporate & $62(28.1)$ & $68.43 \pm 17.39$ & & $66.85 \pm 8.64$ & \\
\hline Type of hospital & Curative & $41(18.1)$ & $63.5 \pm 19.69$ & $\begin{array}{c}t=0.502 \\
d f=225\end{array}$ & $65.67 \pm 8.67$ & $\begin{array}{l}t=1.305 \\
d f=225\end{array}$ \\
\hline & Educational & $186(81.9)$ & $65.12 \pm 18.39$ & $P=0.616$ & $67.86 \pm 9$ & $P=0.193$ \\
\hline Work shift & Rotating & $191(85.7)$ & $65.46 \pm 18.41$ & $\begin{array}{c}t=1.311 \\
d f=221\end{array}$ & $66.96 \pm 8.96$ & $\begin{array}{l}t=1.35 \\
d f=221\end{array}$ \\
\hline & Fixed & $32(14.3)$ & $60.79 \pm 19.96$ & $P=0.191$ & $69.33 \pm 9.04$ & $P=0.168$ \\
\hline Marital status & Single & $76(33.5)$ & $68.81 \pm 20.52$ & $\begin{array}{l}t=2.272 \\
d f=222\end{array}$ & $67.53 \pm 9.92$ & $\begin{array}{l}t=0.396 \\
d f=222\end{array}$ \\
\hline & Married & $148(65.2)$ & $62.87 \pm 17.44$ & $P=0.024$ & $67.03 \pm 8.34$ & $P=0.693$ \\
\hline & $\begin{array}{c}\text { Diploma and college } \\
\text { graduate }\end{array}$ & 59 (39.9) & $65.14 \pm 17.1$ & & $66.79 \pm 8.11$ & \\
\hline $\begin{array}{l}\text { Spouse's } \\
\text { education }\end{array}$ & Undergraduate & $72(48.6)$ & $59.41 \pm 16.53$ & $\begin{array}{l}F=3.051 \\
P=0.051\end{array}$ & $66.77 \pm 8.87$ & $\begin{array}{l}F=0708 \\
P=0.495\end{array}$ \\
\hline & Masters and higher & $17(11.5)$ & $68.92 \pm 19.56$ & & $69.34 \pm 7.26$ & \\
\hline Spouse's occupa- & Employee & $69(48.3)$ & $61.39 \pm 17.46$ & $\begin{array}{c}t=0.976 \\
d f=129\end{array}$ & $67.38 \pm 8.88$ & $\begin{array}{c}t=0.385 \\
d f=129\end{array}$ \\
\hline & Freelancer & $62(43.4)$ & $64.44 \pm 1836$ & $P=0.331$ & $66.81 \pm 8.13$ & $P=0.701$ \\
\hline & 0 & $36(25.4)$ & $58.87 \pm 20.28$ & & $65.33 \pm 7.74$ & \\
\hline Number of & 1 & $54(38)$ & $64.43 \pm 16.36$ & $F=1.6$ & $67 \pm 9.02$ & $F=1.74$ \\
\hline children & 2 & 35 (24.6) & $62.09 \pm 16.77$ & $P=0.192$ & $68.57 \pm 7.21$ & $P=0.162$ \\
\hline & $\geq 3$ & $17(12)$ & $69.49 \pm 16.04$ & & $70.46 \pm 0.10$ & \\
\hline & Good & $44(20.2)$ & $70.76 \pm 17.17$ & & $68.56 \pm 9.23$ & \\
\hline Income & Medium & $157(72)$ & $62.74 \pm 18.89$ & $\begin{array}{l}F=3.248 \\
P=0.041\end{array}$ & $66.91 \pm 8.61$ & $\begin{array}{l}F=0.575 \\
P=0.564\end{array}$ \\
\hline & Poor & $17(7.8)$ & $65.07 \pm 17.6$ & & $67.13 \pm 11.68$ & \\
\hline
\end{tabular}


Table 2. The mean scores of nurses' social health and its dimensions

\begin{tabular}{|ccc|}
\hline Variable & Mean \pm SD & Domain \\
\hline Social prosperity (20-4) & $13.73 \pm 2.76$ & $5-2$ \\
\hline Social solidarity (15.3) & $9.16 \pm 2.34$ & $3-15$ \\
\hline Social cohesion (15.3) & $11.36 \pm 2.58$ & $3-15$ \\
\hline Social acceptance (25-5) & $14.44 \pm 3.19$ & $6-23$ \\
\hline Social participation (25-5) & $18.58 \pm 3.52$ & $7-25$ \\
\hline Total (100-20) & $67.32 \pm 8.96$ & $41-91$ \\
\hline
\end{tabular}

\section{Discussiond}

This study assessed the nurses' quality of life and social health and the relationship between these two variables. We also investigated the relationship between nurses' demographic characteristics, social health, and quality of life. The obtained results revealed that the social health of $78.9 \%$ of the nurses was moderate. No similar research was found in this regard. However, Javadi, N.et al. 2017, examined social health and its related factors among the students of Gilan University of Medical Sciences.

In conclusion, the social health of majority of students was moderate. A study investigated the associated factors of teachers' social health in Maragheh. Their data revealed that the majority of samples enjoyed moder- ate and high levels of social health (Fathi, Ajamnejad \& Khakrangin 2013).

The collected results suggested no significant relationship between social health and the samples' demographic variables. A study examined the social health status of nurses in Ardabil. As a result, correlations were observed between the social health of nurses and their age, gender, work experience, job satisfaction, income, familiarity with nursing at the time of entering this profession, and recruitment opportunity. There was also no significant relationship between nurses' social health and their marital status, education level of spouse or parents, and hospital type (Mozaffari et al. 2014).

Their only result consistent with this study was marital status; however, the results of other variables were not

Table 3. Mean scores of nurses' quality of life and its dimensions

\begin{tabular}{|ccc}
\hline Variable & Mean \pm SD & Score Range \\
\hline Physical function & $83.21 \pm 55.79$ & $100-5$ \\
\hline Roleplay disorder due to physical health & $78.36 \pm 64$ & $100-0$ \\
\hline Roleplay disorder due to emotional health & $97.40 \pm 51.60$ & $100-0$ \\
\hline Fatigue energy & $41.18 \pm 09.59$ & $100-0$ \\
\hline Emotional wellbeing & $36.18 \pm 72.60$ & $100-0$ \\
\hline Social function & $41.23 \pm 2.66$ & $100-0$ \\
\hline Pain & $51.25 \pm 64.67$ & $100-0$ \\
\hline General health & $81.18 \pm 87.60$ & $100-0$ \\
\hline Physical health & $84.19 \pm 02.68$ & $100-25.1$ \\
\hline Mental health & $36.20 \pm 63.61$ & $100-0$ \\
\hline Quality of life & $6.18 \pm 82.64$ & $100-63.0$ \\
\hline
\end{tabular}


Table 4. Correlation coefficients of quality of life and its dimensions with social health and its dimensions

\begin{tabular}{|c|c|c|c|c|c|c|}
\hline \multirow{2}{*}{ Quality of Life } & \multicolumn{6}{|c|}{ Social Health and its Dimensions } \\
\hline & Prosperity & Solidarity & Coherence & Acceptance & Participation & Total \\
\hline Physical health & $\begin{array}{l}r=0.203 \\
P=0.002\end{array}$ & $\begin{array}{l}r=0.058 \\
P=0.387\end{array}$ & $\begin{array}{l}r=0.175 \\
P=0.008\end{array}$ & $\begin{array}{l}r=0.045 \\
P=0.504\end{array}$ & $\begin{array}{l}r=0.216 \\
P=0.001\end{array}$ & $\begin{array}{l}r=0.229 \\
P=0.001\end{array}$ \\
\hline $\begin{array}{l}\text { Roleplay disorder due to } \\
\text { physical health }\end{array}$ & $\begin{array}{l}r=0.272 \\
P<0.001\end{array}$ & $\begin{array}{l}r=0.029 \\
P=0.66\end{array}$ & $\begin{array}{l}r=0.150 \\
P=0.024\end{array}$ & $\begin{array}{l}r=0.175 \\
P=0.008\end{array}$ & $\begin{array}{l}r=0.040 \\
P=0.545\end{array}$ & $\begin{array}{l}r=0.216 \\
P=0.001\end{array}$ \\
\hline $\begin{array}{l}\text { Roleplay disorder role due } \\
\text { to emotional health }\end{array}$ & $\begin{array}{l}r=175.0 \\
P=0.008\end{array}$ & $\begin{array}{l}r=0.107 \\
P=0.109\end{array}$ & $\begin{array}{l}r=0.154 \\
P=0.20\end{array}$ & $\begin{array}{l}r=0.229 \\
P=0.001\end{array}$ & $\begin{array}{l}r=0.187 \\
P=0.005\end{array}$ & $\begin{array}{l}r=0.283 \\
P<0.001\end{array}$ \\
\hline Energy fatigue & $\begin{array}{l}r=286.0 \\
P<0.001\end{array}$ & $\begin{array}{l}r=0.175 \\
P=0.008\end{array}$ & $\begin{array}{l}r=0.182 \\
P=0.006\end{array}$ & $\begin{array}{l}r=0.277 \\
P=0.001\end{array}$ & $\begin{array}{l}r=0.193 \\
P=0.004\end{array}$ & $\begin{array}{l}r=0.344 \\
P<0.001\end{array}$ \\
\hline Emotional wellbeing & $\begin{array}{l}r=328.0 \\
P<0.001\end{array}$ & $\begin{array}{l}r=0.156 \\
P=0.019\end{array}$ & $\begin{array}{l}r=0.240 \\
P<0.001\end{array}$ & $\begin{array}{l}r=0.146 \\
P=0.028\end{array}$ & $\begin{array}{l}r=0.265 \\
P<0.001\end{array}$ & $\begin{array}{l}r=0.366 \\
P<0.001\end{array}$ \\
\hline Social function & $\begin{array}{l}r=306.0 \\
P<0.001\end{array}$ & $\begin{array}{l}r=0.192 \\
P=0.004\end{array}$ & $\begin{array}{l}r=0.188 \\
P=0.004\end{array}$ & $\begin{array}{l}r=0.220 \\
P=0.001\end{array}$ & $\begin{array}{l}r=0.260 \\
P<0.001\end{array}$ & $\begin{array}{l}r=0.380 \\
P<0.001\end{array}$ \\
\hline Pain & $\begin{array}{l}r=323.0 \\
P<0.001\end{array}$ & $\begin{array}{l}r=0.117 \\
P=0.079\end{array}$ & $\begin{array}{l}r=0.166 \\
P=0.012\end{array}$ & $\begin{array}{l}r=0.086 \\
P=0.196\end{array}$ & $\begin{array}{l}r=0.281 \\
P<0.001\end{array}$ & $P<0.001$ \\
\hline General health & $\begin{array}{l}r=239.0 \\
P<0.001\end{array}$ & $\begin{array}{l}r=0.191 \\
P=0.004\end{array}$ & $\begin{array}{l}r=0.266 \\
P<0.001\end{array}$ & $\begin{array}{l}r=0.167 \\
P=0.012\end{array}$ & $\begin{array}{l}r=0.279 \\
P<0.001\end{array}$ & $\begin{array}{l}r=0.361 \\
P<0.001\end{array}$ \\
\hline Physical health & $\begin{array}{l}r=0.343 \\
P<0.001\end{array}$ & $\begin{array}{l}r=0.112 \\
P=0.092\end{array}$ & $\begin{array}{l}r=0.243 \\
P<0.001\end{array}$ & $\begin{array}{l}r=0.161 \\
P=0.015\end{array}$ & $\begin{array}{l}r=0.234 \\
P<0.001\end{array}$ & $\begin{array}{l}r=0.365 \\
P<0.001\end{array}$ \\
\hline Mental health & $\begin{array}{l}r=0.315 \\
P<0.001\end{array}$ & $\begin{array}{l}r=0.481 \\
P=0.006\end{array}$ & $\begin{array}{l}r=0.227 \\
P=0.001\end{array}$ & $\begin{array}{l}r=0.262 \\
P<0.001\end{array}$ & $\begin{array}{l}r=0.272 \\
P<0.001\end{array}$ & $\begin{array}{l}r=0.412 \\
P<0.001\end{array}$ \\
\hline Quality of life & $\begin{array}{l}r=0.355 \\
P<0.001\end{array}$ & $\begin{array}{l}r=0.160 \\
P=0.016\end{array}$ & $\begin{array}{l}r=0.249 \\
P<0.001\end{array}$ & $\begin{array}{l}r=0.229 \\
P<0.001\end{array}$ & $\begin{array}{l}r=0.274 \\
P<0.001\end{array}$ & $\begin{array}{l}r=0.415 \\
P<0.001\end{array}$ \\
\hline
\end{tabular}

consistent with the present study. The incongruence between the studies could be due to the differences in the studied samples, the cultural and economic status, and the hospitals' conditions.

A study was conducted on the social health of the students of Guilan University of Medical Sciences and its related factors. Accordingly, a significant relationship was observed between social health and gender, age, and educational variables; however, no it was not associated with marital status (Javadi et al. 2017). Another study also reported a significant relationship between social health and age, sex, and education (Fathi, Ajamnejad \& Khakrangin 2013).

The incongruence between these findings and ours could be because of different sample sizes. In addition, individuals with higher educational level have more employment opportunities. Thus, arranging working hours with class schedules can cause extensive pressure, affecting their social health.

Our study revealed that the scores of quality of life and all its aspects were higher than the median tool score of 50. There was only a significant relationship between age, work experience, marital status, and income, and the quality of life. Another study also indicated that the quality of life had been significantly related to marital status and working hours (Khaghanizadeh, Ebadi \& Rahmani 2008). Vahed et al. (2011) documented a significant relationship between the quality of working life and gender, marital status, and work experience; the quality of working life of men, married nurses, and those employees with work experience of more than 20 years was higher. Their results were consistent with those of our study. However, another study reported no significant relationship between the quality of life and gender, marital status, and working hours (Najafi et al. 2018).

The reason for such inconsistent results could be inaccurate responses to the quality of life questionnaire, as well as the difference between the research tools. Other reasons for the dissimilarity of the findings could be the difference between the research environment, hospital situations, and the nurses' working conditions.

To compare the results of this study in terms of marriage, a study revealed no significant relationship between the quality of life and marital status (Allaf Javadi et al. 2010). However, another study indicated that marital status was associated with the nurses' quality of life (Habibzadeh et al. 2012). 
Our study revealed a positive and significant relationship between the quality of life and its aspects with social health. This means that with an increase in the quality of life, nurses' social health will also improve. Nurses' suitable social health and the quality of working life lead to a better and more creative planning for providing their services (Vahed et al. 2011). No similar research was found in this respect. However, a study investigated the effect of social health on students' quality of life in Payame Noor University of Meshkin Shahr. There was a positive and significant correlation between social health and quality of life of students; thus, social health had a significant relationship with the 4 dimensions of quality of life, including physical health, mental health, social relations health, and environmental health (Aghdam et al. 2013).

In another study, the relationship between job satisfaction and nurses' quality of life was assessed in Taiwan. In conclusion, a direct relationship was reported by nurses between their quality of life and health status (Cheng \& Huang, 2014). Furthermore, another health dimension that affects the quality of life is spiritual well-being. This aspect was investigated in a study by Asarrodi et al. They assessed the relationship between nurses' spiritual wellbeing and their quality of life. Their findings suggested that the mean scores of quality of life and spiritual wellbeing in both genders were not significantly different. There was also a positive and significant relationship between spiritual well-being and the different aspects of quality of life (Asarrodi, Golafshan \& Akabari 2011).

According to the study findings, there was a significant relationship between nurses' social health and their quality of life. These findings provide preliminary information for future empirical studies to improve the quality of life and social health of nurses. Moreover, the obtained data can be used by health authorities to identify the necessary corrective factors to improve nurses' social health and quality of life.

\section{Ethical Considerations}

\section{Compliance with ethical guidelines}

IUMS Research Committee approved the study (Code: IR.IUMS.FMD.REC 139609511690001). Agreement of the hospitals was acquired, and research objectives were explained about the study units. Written consent was also obtained from all study participants. Explanations related to the completion of the questionnaires were presented to the study participants.

\section{Funding}

The present paper was extracted from the MSc. thesis of the second author, Department of Community Health Nursing, School of Nursing and Midwifery, Iran University of Medical Sciences.

\section{Authors' contributions}

Conceptualization: Parvin Ehyaei, Marhamat Farahaninia, Zahra Ahmadi; Methodology: Parvin Ehyaei, Marhamat Farahaninia and Hamid Haghani; Investigation: Parvin Ehyaei; Writing-original draft, Writing-review and editing: Parvin Ehyaei, Marhamat Farahaninia; and Supervision: Marhamat Farahaninia.

\section{Conflict of interest}

There are no conflicts of interest to be declared by the authors.

\section{Acknowledgments}

Authors would like to thank Iran University of Medical Sciences, Faculty of Nursing and Midwifery, Research Deputy of IUMS, the authorities and nurses of Lolagar, Yaft Abad, Firoozgar, Motahari, and Rasool Akram Hospitals, and all those involved in the research are appreciated.

\section{References}

Aalaa, M., et al. 2012. Assessment of quality of life of Iranian nurses. Nursing Reports, 2(1), pp. 10-7. [DOI:10.4081/ nursrep.2012.e10]

Afshani, S., et al. 2014. [The investigation into the relationship between islamic life style and social health among people of Yazd City (Persian)]. Biquarterly journal of Studies in Islam \& Psychology, 8(14), pp. 83-103.

Aghdam, M. B., et al. 2013. [Studying the impact of social health on quality of life of students in Payame-Noor University in Meshginshahr City (Persian)]. Institute of Social Studies and Research, 2(4), pp. 525-64.

Alaeenejad, A., et al. 2017. Relationship between health-promoting behaviors and quality of life in postmenopausal women Journal of Client-Centered Nursing Care, 3(4), pp. 269-76. [DOI:10.32598/jccnc.3.4.269]

Allaf Javadi, M., et al. 2010. [Comparison of life quality between special care units and internal-surgical nurses (Persian)]. Journal of Critical Care Nursing, 3(3), pp. 9-10. 
Ansari, H. \& Abbasi, M., 2015. [Health-related quality of life among nurses in Zahedan University of Medical Sciences Hospitals (Persian)]. Journal of Hospital, 14(3), pp. 47-55.

Asarrodi, A., Golafshan, A. \& Akabari, A., 2011. [Relationship of between spiritual health and quality of life in nurses (Persian)]. Journal of North Khorasan University of Medical Sciences, 3(4), pp. 81-8. [DOI:10.29252/jnkums.3.4.79]

Babapour Kheiroddin, J., Toosi, F. \& Hekmati, I., 2010. [Study of determinant factors role of students' social well-being (Persian)]. Journal of Psychology, 16(4), pp. 1-19.

Cheng, C. H. \& Huang, C. J., 2014. Relationship of job satisfaction and quality of life among Taiwanese nurses: A pilot study. paper presented at: 25th International Nursing Research Congress. 2014 November 17, Hong Kong, China.

Dargahi, H. \& Yazdi, M. S., 2007. Quality of work life in Tehran University of Medical Sciences Hospitals' clinical laboratories employees. Pakistan Journal of Medical Sciences, 23(4), pp. 630-3.

Fallahee Khoshknab, M., et al. 2007. [Quality of life and factors related to it among psychiatric nurses in the university teaching hospitals in Tehran (Persian)]. Hakim Research Journal, 9(4), pp. 24-30.

Fathi, M., Ajamnejad, R. \& Khakrangin, M., 2013. [Factors contributing to social health among teachers of Maraghe City (Persian)]. Social Welfare Quarterly, 12(47), pp. 225-43.

Grady, C., et al. 2008. Does ethics education influence the moral action of practicing nurses and social workers? The American Journal of Bioethics, 8(4), pp. 4-11. [DOI:10.1080/15265160802166017] [PMID] [PMCID]

Habibzadeh, H., et al. 2012. [The relationship betweennurses' quality of work life and their clinical competency (Persian)]. The Journal of Urmia Nursing and Midwifery Faculty, 10(3), pp. 332-339.

Heidari, F. \& Mohammadkhan-Kermanshahi, S., 2012. [Health related lifestyle in nurses (Persian)]. Journal of Health and Care, 14(3), pp. 23-33.

Hsu, M. Y. \& Kernohan, G., 2006. Dimensions of hospital nurses' quality of working life. Journal of Advanced Nursing, 54(1), pp. 120-131. [DOI:10.1111/j.1365-2648.2006.03788.x] [PMID]

Jannati, Y., Mohammadi, R. \& Seyedfatemi, N., 2011. Iranian clinical nurses' coping strategies for job stress. Journal of Occupational Health, 53(2), pp. 123-9. [DOI:10.1539/joh.O10015] [PMID]

Javadi, N.et al. 2017. [The survey of social wellbeing and related factors in students of Guilan Medical University in 2015 (Persian)]. Research in Medicine, 40(4), pp. 197-203.

Keles, R., 2012. The quality of life and the environment. Procedia-Social and Behavioral Sciences, 35(2012), pp. 23-32. [DOI:10.1016/j.sbspro.2012.02.059]

Keyes, C. L. \& Shapiro, A. D., 2004. Social well-being in the United States: A descriptive epidemiology. How healthy are we, 15(3), pp. 350-72.

Khaghanizadeh, M., Ebadi, A. \& Rahmani, M., 2008. [The study of relationship between job stress and quality of work life of nurses in military hospitals (Persian)]. Journal of Military Medicine, 10(3), pp. 175-84.
Maghsoodi, S., Hesabi, M. \& Monfared, A., 2015. [General health and related factors in employed nurses in Medical-Educational Centers in Rasht (Persian). Journal of Holistic Nursing and Midwifery, 25(1), pp. 63-72.

Maslakpak, M., Ahmadi, F. \& Anoosheh, M., 2011. [Spiritual beliefs and quality of life: A qualitative research about diabetic adolescent girls' perception (Persian)]. Koomesh, 12(2), pp. 144-51.

Mokarami, H., Taghavi, S. \& Taban, E., 2016. [Psychosocial factors and Their Relationship to health-related quality of life in an industrial factory in Yasuj City (Persian)]. Iran Occupational Health, 12(6), pp. 69-80.

Mozaffari, N., et al. 2014. [The status of social well-being in Iranian nurses: A cross-sectional study (Persian)]. Journal of Caring Sciences, 3(4), pp. 239.

Najafi, F., Kermansaravi, F. \& Gangoozehi, E., 2018. [The relationship between general health and quality of work life of nurses working in Zahedan teaching hospitals (Persian)]. Iranian Journal of Rehabilitation Research. 2018; 4 (2):53-9.

Noghabi, A. A., Alhani, F. \& Peyrovi, H., 2013. Health hybrid concept analysis in old people. Global Journal of Health Science, 5(6), pp. 227-32. [DOI:10.5539/gjhs.v5n6p227] [PMID] [PMCID]

Ramadan, E. \& Ahmed, H., 2015. The effect of health educational program on depression, anxiety and stress among female nursing students at Benha University. IOSR Journal of Nursing and Health Science, 4(3), pp. 49-56.

Rostamigooran, N., et al. 2013. Health system vision of Iran in 2025. Iranian Journal of Public Health, 42(Suppl. 1), pp. 18-22. [PMID] [PMCID]

Sharbatiyan, M. H., 2012. The semantic components reflecting the link between social capital and the rate social health of the benefit of students of Payam Noor University, Mashhad. The Sociology of the Youth Studies Quarterly, 2(5), pp. 149-74.

Tavakol, M., 2015. [Social Health: Dimensions, components, and indicators in Iranian and world studies (Persian)]. Bioethics Journal, 4(14), pp. 115-35.

Vahed, A. S., et al. 2011. [Assessment of the items of SCL90 test with quality of work life among Amiralmomenin Hospital personnel of Zabol City (Persian)]. Scientific Journal of Hamadan University of Medical Sciences, 18(2), pp. 50-55.

World Health Organiation, 2016. Global strategic directions for strengthening nursing and midwifery 2016-2020. Geneva: World Health Organiation. 
This Page Intentionally Left Blank 